\title{
Lessons Learned: Nurses' Experiences with Errors in Nursing
}

Amy R. Koehn, Patricia R. Ebright, Claire Burke Draucker

Introduction. A 2000 Institute of Medicine (IOM) report To Err Is Human

provided estimates of the number of medical errors that occur nationwide and concluded

that $44,000-98,000$ patients die annually as a result of preventable medical errors (Kohn,

Corrigan, \& Donaldson, 2000).Goodman, Villarreal, and Jones (2011) multiplied the IOM

estimates of patient deaths by the median social cost of injury as described by Viscusi

(2003) and estimated the cost of preventable inpatient injuries at $\$ 6.7$ billion. This value of

a statistical life (VSL) is an important parameter in assigning monetary value to health

risks (Doucouliagos, Stanley \& Viscusi, 2014).

Although in 2000 the IOM called for a 50\% reduction in medical errors within 5

years, this decrease has not occurred despite the development of several error-reduction

interventions (Leape et al., 2009). The lack of demonstrable reduction in errors has been

attributed to several factors including inconsistencies in reporting mechanisms across

organizations, variations in how errors are measured in research, and the inability to

accurately identify the percentage of actual errors reported by healthcare providers. High

rates of medical errors persist within healthcare systems despite efforts to develop a culture

This is the author's manuscript of the article published in final edited form as:

Koehn, A. R., Ebright, P. R., \& Draucker, C. B. (2016). Nurses' experiences with errors in nursing. Nursing Outlook, 64(6), 566-574. https://doi.org/10.1016/j.outlook.2016.05.012 
of safety within hospitals and a push to make healthcare systems high reliability organizations (HROs) (Hershey, 2015). High reliability organizations are characterized by attention to failure, the reluctance to simplify understanding of systems and processes, and a focus on what happens at the point where real work is completed and reliance on the expertise of those who perform the real work (Weick \& Sutcliffe, 2007). To move health care toward more reliable performance and outcomes, detailed understanding of the work of nursing, the processes and systems that touch their work, and learning about what happens when these processes and systems fail is critical. The ultimate goal of reporting is for increased learning about why things go wrong and to improve systems and outcomes.

Determining rates of medical errors in healthcare systems in the United States (US) has been problematic due in part to the lack of systematic reporting procedures (AHRQ, 2010; Pham, Frick, \& Pronovost, 2013; Pronovost, Miller, \& Wachter, 2006). Accurate counts of deaths or injuries attributed to medical errors are also hard to obtain due to the variations in legal, cultural, and administrative approaches to reporting errors (Anderson, Kodate, Walters \& Dodds, 2013; Loeb \& O'Leary, 2004). James (2013) reviewed four studies which used the Global Trigger Tool (Griffin \& Resar, 2009) to track patient adverse events and estimated that 210,000 to 400,000 of these adverse events occur 
yearly. Subsequent studies have reinforced these findings and the utility of the Global Trigger Tool (Harkanen et al., 2015; Mull et al., 2015). The failure to demonstrate reduction of errors also may be a result of differences in research methodology, such as variations in the way error reporting is measured, rather than lack of safety in hospitals (Goodman et al., 2011). Accurate determination of error reporting is needed to determine the efficacy of error reduction interventions.

The Patient Safety and Quality Improvement Act of 2005 was designed "to improve patient safety by encouraging voluntary and confidential reporting of events that adversely affect patients" (AHRQ, 2010). This legislation prompted the creation of patient safety organizations (PSOs) charged with identifying error patterns by analyzing large numbers of error reports from diverse sources so that threats to patient safety could be identified and interventions could be developed to reduce risks to patients (Kachalia, Mello, Nallamothu,\& Studdert, 2016; Clancy, 2008). Licensed nurses (registered nurses [RNs], licensed practical nurses [LPNs]) and unlicensed nursing assistants (UNAs) comprise $54 \%$ of the healthcare workers in the United States (Page, 2004). Complete information given to PSOs by licensed nurses is critical to the accuracy and dependability of patient safety databases. 
When nurses make, discover, or observe an error during the course of their

practice, they must decide whether or not to make a formal report. Although nurses are the healthcare professionals who most frequently report errors, many continue to harbor fears about reporting them (Bayazidi, Zraezadeh, Zamanzadeh, \& Parvan, 2012; Cook, Hoas, Guttmannova, \& Joyner, 2004; Espin, Lingard, Baker, \& Regehr, 2006; Hartnell MacKinnon, Sketris, \& Fleming, 2012;Osmon et al., 2004; Rowin et al., 2008; Prang \& Jelsness-Jorgensen, 2014; Uribe, Schweikhart, Pathak, Dow, \& Marsh, 2002). In many institutions, the workplace culture regarding error reporting remains one of blame, and nurses are often concerned about personal repercussions associated with reporting errors (Blair, Kable, Courtney-Pratt, \& Doran,2015; Castel, Ginsburg, Zaheer, \& Tamin, 2015; Cook et al., 2004; Espin et al., 2006; Jeffe et al., 2004; Stratton, Blegen, Pepper, \& Vaughn, 2004; Taylor et al., 2004; Uribe et al., 2002). A better understanding of nurses' decision-making regarding error reporting and workplace factors that influence their decisions can inform the development of strategies to improve the frequency and accuracy of error reporting by nurses. The purpose of this study, therefore, was to explore nurses' decision-making processes regarding reporting errors.

Methods. Grounded theory (GT) methods guided this study. GT is an approach used to develop a theoretical framework that describes a psychosocial process shared by a 
group of individuals who face a common challenge and who are influenced by a sociocultural context that affects the collective (Charmaz, 2014; Glaser \& Strauss, 1967). Through an iterative process of data collection and analysis, participant narratives about the phenomenon of interest served as the basis for the development of a theoretical framework (Charmaz, 2014).

Sample. Licensed registered nurses who worked in an adult intensive care unit (ICU) as direct patient caregivers comprised the study sample. ICUs were chosen because high rates of errors are reported on nursing units that provide acute care for critically ill patients, such as intensive care units (Brunsveld-Reinders, Arbous, De Vos, \& De Jonge, 2016; Landrigan et al., 2004), and critically ill patients experience higher rates of adverse events and errors than other patient populations (Balas, Scott, \& Rogers, 2006; Kiekkas, Karga, Lemonidou, Aretha, Karanikolas, 2011).

Convenience sampling was used to recruit licensed nurses from eight ICUs within an urban university-affiliated hospital organization between November 2012 and June 2013. Following approval from the university Institutional Review Board (IRB), which was honored by the hospital organizations in lieu of separate approvals, emails explaining the study were sent to three chief nursing officers (CNOs). 
The CNOs provided access to department directors and unit managers. Following approval from each unit manager, the researcher spent time on each unit to observe and be present with the nurses. During these visits, the researcher initiated discussions regarding the study, provided details for those who appeared interested in participating, and collected contact information from those who agreed to be interviewed.

Interviews. Individual interviews were conducted at a mutually arranged time in a private location away from the nurses' home unit. A brief purpose statement was read indicating that no information shared during the interviews would be acted upon outside of the research process.

All participants signed an informed consent document that was labeled with an anonymous identification (ID) number linking data collected during the interview and any subsequent memos about the interview.

In order to remove implications of blame and normalize the experience of making an error, questions were phrased to indicate that errors are a universal occurrence in nursing care and everyone likely has an error experience to share. The interview began by asking the nurses to recall an error-related event that had "stuck" with them. Most of the nurses freely discussed their experiences of making an error, and the researcher used brief prompts throughout the interviews to encourage the participants to fully describe their 
experiences. The interviews lasted between 40 and 60 minutes, and the nurses were given a $\$ 25$ gift card to a major discount store as compensation for their time. The interviews were digitally recorded and transcribed.

Data Analysis. Data collection and analysis progressed simultaneously. Procedures outlined by Charmaz (2014) were used to analyze the data. These procedures are based on a strategy referred to as constant comparison analysis, which is a process whereby data are compared within and across narratives and increasingly abstract theoretical renderings of the data are generated. The process begins with initial coding in which relevant text units (e.g., words, phrases, or sentences that are related to the phenomenon of interest) are extracted and given a label that captures their meaning. The next step is focused coding in which codes are compared for similarities and difference and categories comprised of similar codes are developed and labeled. In axial coding, relationships among categories are proposed, validated with a return to the narrative data, and linked into a theoretical framework. Initial coding was conducted by the first author, and focused and axial coding were completed by the full research team through processes of discussion and consensus. Memos were used to document all analytic decisions.

All study participants were female and Caucasian except for one African-American nurse. The average age of the participants was 34 years of age (range 22 years to 63 years), and their average number of years as a registered nurse was 9.5 years (range 1.5 
years to 40 years). On average, the participants had been at their current position for 4.3

years (range 1 year to 19 years).

Although the participants described observing, and in some cases reporting,

medical errors made by others, they mostly described errors that they had made

themselves. Because the personal experience of making an error differed significantly from

observing or discovering the error of another, the participants' experiences with errors they

made are the focus of the study.

The findings indicate that making an error while providing nursing care was a

personal, memorable, and distressing experience and was unrelated to the age of level of experience of the nurse. The participants' responses to having made an error varied, but evident in all their narratives was the sense that they learned from the error so as to never make that same error again. These lessons remained with participants throughout their careers. The process surrounding the occurrence and reporting/not reporting of an error was thus labeled "Learning Lessons from the Error." The processes of "Learning Lessons from the Error" included five stages: Being Off-Kilter, Living the Error; Reporting/Telling About the Error, Living the Aftermath, and Lurking in Your Mind. (See Figure 1). The five stages are described below.

\section{Insert model here}


Being Off-Kilter. The label "Being Off-Kilter" was chosen for the first stage because the errors made by participants often occurred in the context of working conditions that were challenging or that flustered them in some way. Some participants were off-kilter because they were unaccustomed to the demands of the work. Many were "fairly new" and still learning their "new role" when they made the error. Others were experienced nurses but were working on a unit that was unfamiliar to them. Several of these participants, for example, indicated that the error occurred when they were "floated" to an unfamiliar unit without much orientation to the unit. One participant with five years of experience said that floating to another unit "throws a nurse off her kilter and what she's used to." Many of the participants made an error when they felt particularly taxed by the demands placed on them that day. Their shift was "super hectic," and they were "really stressed out" because they needed to prioritize multiple tasks. Several participants encountered obstacles in their environment that impeded their work and contributed to their error. These participants needed to use equipment that was not functioning properly, did not have the help they needed to meet the demands of their assignments, or worked with coworkers who were difficult. These participants felt like they were "out on a limb."

Living the Error. The label "Living the Error" was chosen for the second stage because of the consuming and personal nature of these error experiences. Most of 
participants told vivid and detailed stories about making an error and described the intense emotions that surrounded the experience. Most of the errors were medication errors, but participants also described inadvertent extubations, misuse of equipment, and the mislabeling of laboratory specimens. Participants often first became alerted to the error when they realized that something about the patient or situation "just wasn't clicking." The participants then reviewed their previous actions caring for the patient before putting "two and two together" and realizing they had made an error. At this moment, most of the participants blurted something to the effect of "Oh, my God" or used an expletive to describe how distraught they felt. One participant with 19 years of experience stated, “...It just hit me...I could have passed out. I mean honestly I was so sick to my stomach.” Several participants then engaged in frantic efforts to figure out what went wrong and to correct the error in some way. One participant said that all she could think of was "making it right." For most of the situations, correcting the error generally required only minor actions. Others errors were not as easily "fixed" and required remedial actions such as notifying the pharmacist to correct a medication error or adjusting a dialysis schedule due to a pump malfunction. All the participants described feeling anguish about the error. Most blamed and berated themselves and questioned their abilities as a nurse. One participant with nine years of experience stated, "I felt like an idiot [that] I let [the error] 
happen." The anguish often persisted throughout the day of the error and the days that followed.

Reporting or Telling About the Error. The label "Reporting or Telling About the Error" was chosen for the third stage because it reflects the varied ways in which the error became known to others in the workplace. All the participants discussed whether, when, and how they revealed the error to others. The disclosing (or not disclosing) of the error happened in four different circumstances. The label reporting the error was chosen to describe circumstances when the participants formally reported the error to a manager and/or completed an incident report. Most of the participants who reported an error did so because it was expected of them even if the error did not threaten the patient. Reporting certain types of errors had become "very standard" where some participants worked and their managers had really "drilled home" the need for error reports in certain situations. In these situations, the errors were often related to quality indicators, such as patient falls or urinary tract infections, which the units were tracking as part of a hospital's safety initiative.

The label telling the error was chosen to describe circumstances when participants told a physician or another medical staff person about the error, not to initiate formal reporting but rather to protect the patient from harm. One participant with four years of 
experience said, "I knew that if I told [the physicians]...that maybe there would be something that we could do." Another participant with 23 years of experienced stated, "I called the doctor and to me that is my incident report." Other participants told nurse colleagues about an error to enlist their help with or get their opinions about how the error could be mitigated.

The label not reporting or telling about the error was used to describe circumstances in which participants did not tell anyone in their workplace about the error they had made. Some participants revealed that it was not necessary to tell because the error was easily corrected or because the patient had not been harmed. Though none of the participants indicated that they actively hid the error, some said that telling others did not occur to them. None of the participants indicated they withheld reporting or telling the error out of fear of punishment; in fact, they were able to voice the ideals of just culture espoused by their institution. One participant with three years of experience simply stated, "I guess it never really crossed my mind [to tell] ...because it got interrupted before it got to the patient."

The label being reported on about the error was used to describe circumstances in which others discovered the error and "reported on" the participants. These participants were more likely to be subjected to disciplinary actions by nursing administration or to be 
"scolded" by physicians. These participants were also more like to be asked "why" they made the error and to feel blamed. Some participants were reminded that they had been "written up" previously and advised that further reports would be "a big deal." A participant with seven years of experience related being told, "[The error is] your error; you missed it. You were the initial...., you were the instigator."

Living the Aftermath. The label "Living the Aftermath" was chosen for the fourth stage because the participants were often plagued by memories of the error even after it was resolved and were determined not to have it happen again. Because the participants' institutions often provided no follow-up even if an error report was filed, the participants were often left to process the error and make sense of it alone. None of the participants reported being involved in a root cause analysis (RCA) or noting changes to the unit's practices after the error. One participant with 2.5 years of experience stated, "I think maybe someone would ever one day care about what happened and ask me, but nobody ever does."

In the aftermath of the error, the participants often tried to understand why it occurred and to consider how it could have been avoided. These ruminations seemed to serve the purpose of learning a lesson to avoid making a similar error again. One participant with six years of experience proclaimed, "I have not made a mistake like that 
since." Participants were especially committed to avoid actions that might result in patient harm in the future. The understanding the nurses gained as a result of the error often led to changes in their daily routine or practice.

Participants thus believed that some benefit came from the error because of the painful personal lessons learned. Unfortunately, this learning was not shared with other nurses working in the same environments, or similar situations, which may have led to changes that would decrease complexity and improve systems which would support the work rather than contribute to errors.

Lurking in your Mind. The label "Lurking in your Mind" was chosen for the final stage because most participants believed that their memories of making an error would never go away or even dampen. The participants were convinced that these memories would "stick with" them throughout their careers and continue to influence their practice. The term lurk reflects that participants did not often discuss the memories of the error and the feelings associated with it but these memories and feelings remained under the surface and continued to haunt them. One participant with 14 years of experience stated, “... I even remember what room it [error] was in...bed [number]. That stuff is imprinted in your mind." 
Because the experience of the error lurked in the minds of the participants, they maintained an enduring vigilance to ensure a similar error did not occur again. In this sense, lurking could have a positive connotation. The participants claimed that having been through an made them "pay closer attention" when they were in a similar situation. Some even vocalized how making an error is a necessary part of learning about how to be a nurse. The "lessons we remember" lead to naming the theoretical model, "Learning Lessons from the Error".

Discussion \& Recommendations. Despite the crucial role of nurses in reporting medical errors to advance initiatives to improve patient safety, few studies have examined the experience of making an error and reporting it (or not reporting it) from nurses' perspectives. In this study, the process of deciding whether or not to report an error was placed in the context of a more overarching process which we labeled "Learning Lessons from the Error." When nurses shared stories of the medical errors they had made, they provided vivid accounts of the circumstances that led to the error, the moment when they realized they made the error, the decision whether or not to report the error, suffering alone in the days that followed the error, and having memories of the error that endured throughout their careers. 
The findings of this study add to the literature by describing the experience of making a medical error as a complex and nuanced process. For example, researchers typically have not differentiated between formal and informal error reporting (Covell \& Ritchie, 2009; Crigger \& Meek, 2007; Elder, Brungs, Nagy, Kudel, \& Render, 2008) whereas our findings suggest that these are two different types of experiences with differing implications. Some studies have explored nurses' attitudes and immediate responses to errors but have not explored how nurses cope with having made an error over time (Sirriyeh, Lawton, Gardner, \& Armitage, 2010). Our findings highlight how making an error affects nurses over the course of their careers-even years after it occurred. Similar themes are found in the medical literature regarding physician's acceptance of the error and integration of the experience into their view of themselves (Plews-Ogan, Owens, \& May, 2013). Variations in the nurse's work environment shaped both the origin of and response to the error and impacted the ability of the nurse to provide high quality care (Steege, Drake, Olivas \& Mazza, 2015). The contributions of complex environmental factors that characterize nursing work and lead to failures in delivery of care are well documented in the literature (Sitterding, Ebright, Broome \& Patterson, 2014; Foroungi, Weber et al. 2013; Hopkinson \& Jennings, 2013; Ebright, 2010; Hall et al., 2010; ). That nurses participating in this study were able to recall details surrounding an error supports 
the notion that retrieving details of an event from those involved in the situation is a productive method for learning why things happened the way they did. Having a nurse describe what was happening during the time she felt "off kilter" could lead to process and structural changes that mitigate the complexity of environments.

In 2000, A. Wu introduced the idea of physicians becoming "second victims" (Wu, 2000, p. 726) following a medical error and continues to study the effects of errors on healthcare professionals (Wu \& Steckelberg, 2012). This concept has subsequently been translated to nursing practice (Jones, \& Treiber, 2012; Scott et al., 2009). Scott et al. (2009) defined the second victim as: "healthcare providers who ... become traumatized by the [error]. Frequently these individuals feel personally responsible for the unexpected patient outcome" (p. 326). One study revealed that as many as half of all healthcare providers have become second victims at some point in their professional career (Seys et al., 2013). As 'second victims,' individuals were affected in both their personal and professional lives (Schelbred \& Nord, 2007) and/or experienced serious long-term emotional consequences (Karga et al., 2011). After being involved in an error, many nurses neither received the support they needed nor knew where to find such support (Scott et al., 2009; Waterman et al., 2007). Most health care institutions did not have 
adequate support systems in place to assist staff with coping and adapting after an error (Gallagher et al., 2003; Schwappach \& Boluarte, 2008).

Our findings highlight how institutional procedures and practices regarding error reporting influence nurses' experiences. The participants stressed that their organizations never provided follow-up about the errors that they had reported, such as providing information about actions taken, which then impeded their learning. Consistent with these findings, Benn et al. (2009) noted that although sharing information about errors is critical for organizational advancement, there is considerable variation in the feedback mechanisms associated with reporting procedures. In addition to receiving no follow-up information, few participants were offered institutional help to cope with the personal toll of having made an error, and this often led to a sense of shame and isolation. A systematic review of literature by Sirriyeh et al. (2010) revealed that the majority of studies described attitudes about and immediate responses to an error rather than uncovering the management, coping and/or longer-term outcomes of errors. Sirriyeh et al. (2010) discussed how current research fell short in addressing how individuals cope with an error. Others agreed there was sparse evidence to guide the understanding of the providers' experiences with errors (Lewis et al., 2013) and that diverse measures were necessary to explore and understand how individuals experienced and coped with errors in the longer 
term, including its contribution to nursing burnout (Lewis, Baernholdt, Yah, \& Guterbock, 2015; Sirriyeh et al., 2010). Recently, Bodenbeimer \& Sinsky (2014) proposed an additional fourth goal to the 'Triple Aim' approach to healthcare introduced by Berwick (2008) which focuses on improving the work life of all healthcare providers. Finally, the number of individuals affected is also unknown because the means to accurately identify the number of nurses who incur significant suffering from medical errors does not currently exist (Hall \& Scott, 2012; Paparella, 2011).

The only participants who experienced little distress following errors and who reported them matter-of-factly without expecting negative repercussions were those who had made errors that were the focus of a tracking initiative on their units related to nurse sensitive indicators (NSIs). NSIs are defined as "patient care measures that reflect the impact of nursing actions on outcomes" (Commission on Magnet, 2005, p. 81). Unit initiatives such as those that aim to reduce patient falls or prevent urinary tract infections may reduce the stigma of reporting errors and instead focus on enhanced quality improvement and patient safety. Overall, this study demonstrated the confusion and variation that existed for these nurses about what constitutes a reportable error, and to whom and how to report it, consistent with existing research on error reporting. 
Recommendations. The findings of this study suggest that organizational strategies are needed not only to encourage nurses to report errors but to support nurses when they make an error. At the most basic level, institutions need to follow up with nurses who report an error both to inform them of actions taken but also to acknowledge and help diminish their distress. Nurses should be privy to system-wide error information as this would promote collective contextual learning and spare nurses from learning lessons on their own based only on their private understandings of what led to the error. Future research should focus on the development of strategies to facilitate error reporting by obtaining nurses' perspectives on what they would need to facilitate learning and coping in the aftermath of an error and an error report. As this study did not collect data regarding the actual timing of the error in relation to how long the nurses had practice, , future research should be conducted to investigate differences in the error experience between new grads and experienced nurses as these differences might require alternative approaches to support in the aftermath.

Limitations. One major limitation of the current study is that we did not obtain nurses' narratives about errors that resulted in serious patient harm or death. These nurses may be reluctant to participant in research due to shame or fear of repercussions. Future research should explore the experiences of nurses whose errors have led to dire patient 
outcomes because error reporting may be a particularly unique experience for them. In addition, the current study was completed only in intensive care units where all participants were employed on the day shift and all but one of the participants were Caucasian. Future studies of nurses' decision-making about reporting errors should be conducted in varied work environments and with populations that are more demographically diverse. This study is also not generalizable to the newly graduated nurse as most of the participants had 9.5 years' experience as a nurse. Future studies should explore potential difference in the experience of making an error for the newly graduated and the experienced nurse.

Conclusion. This study used grounded theory to analyze interviews of 30 participants from adult intensive care units in order to explore their experiences with medical errors. Making an error is a complex dynamic process often situated in the context of a high-stress working environment. The nurses' most salient response to making an error was learning from the error so it would not happen again. Making an error is typically a highly distressing experience for nurses, and lack of institutional follow-up and support exacerbates this distress. New institutional strategies are needed to assist nurses who make errors in order to advance patient safety initiatives related to error reporting. 
Acknowledgements. Sincere gratitude goes out to the University School of

Nursing Student Nursing Research Proposal Funding and the Dissertation Scholarship Award for their funding resources. 


\section{References}

AHRQ. (2010). The patient safety and quality improvement act of 2005: Overview. Retrieved from http://www.ahrq.gov/qual/psoact.htm.

Anderson, J., Kodate, N., Walters, R., \& Dodds, A. (2013). Can incident reporting improve safety? Healthcare practitioners' views of the effectiveness of incident reporting. International Journal for Quality in Health Care, 25(2) 141-150. doi: 10.1093/intqhe/mzs081

Balas, M. C., Scott, L. D., \& Rogers, A. E. (2006). Frequency and type of errors and near errors reported by critical care nurses. Can J Nurs Res, 38(2), 24-41. Retrieved from http://www.ncbi.nlm.nih.gov/pubmed/16871848.

Bayazidi, S., Zraezadeh, Y., Zamanzadeh, V., \& Parvan, K. (2012). Medication error reporting rates and its barriers and facilitators among nurses. Journal of Caring Sciences, 1(4). 231-236. doi: 10.5681/jcs.2012.032

Benn, J., Koutantji, M., Wallace, L., Spurgeon, P., Rejman, M., Healey, A., \& Vincent, C. (2009). Feedback from incident reporting: information and action to improve patient safety. Qual Saf Health Care, 18(1), 11-21. doi:10.1136/qshc.2007.024166.

Berwick, D., Nolan, T. \& Whittington, J. (2008). The Triple Aim: care, health, and cost. Health Aff (Millwood, 27(3). 759-769.

Blair, W., Kable, A., Courtney-Pratt, H., \& Doran, E. (2015). Mixed method integrative review exploring nurses' recognition and response to unsafe practice. Journal of Advanced Nursing,3. 488-500. doi:10.1111/jan.12855

Bodenbeimer, T. \& Sinsky, C. (2014). From Triple to Quadruple Aim: Care of the Patient Requires Care of the Provider. Annals of Family Medicine, 12(6). 573-576.

Brunsveld-Reinders, A., Arbous, M., De Vos, R., \& De Jonge, E. (2016). Incident and error reporting systems in intensive care: a systematic review of the literature. Int J Qual Health Care, 28(1). 2-13. doi: /10.1093/intqhe/mzv100

Castel, E., Ginsburg, L., Zaheer, S., \& Tamin, H. (2015). Understanding nurses' and physicians' fear of repercussions for reporting errors: clinician characteristics, organization demographics, or leadership factors? BMC Health Services Research,15 (326). 1-10. doi: 10.1186/s12913-015-0987-9

Charmaz, K. (2014). Constructing grounded theory (2nd edition. ed.). Thousand Oaks, CA: Sage Publications. 
Clancy, C. M. (2008). New patient safety organizations lower roadblocks to medical error reporting. Am J Med Qual, 23(4), 318-321.

doi:10.1177/1062860608319673Commission on Magnet. (2005). The Magnet recognition program: Application manual. Silver Spring, MD: American Nurses Credentialing Center.

Cook, A. F., Hoas, H., Guttmannova, K., \& Joyner, J. C. (2004). An error by any other name. Am J Nurs, 104(6), 32-43; quiz 44. Retrieved from http://www.ncbi.nlm.nih.gov/pubmed/15187607

Covell, C. L., \& Ritchie, J. A. (2009). Nurses' responses to medication errors: suggestions for the development of organizational strategies to improve reporting. J Nurs Care Qual, 24(4), 287-297. doi:10.1097/NCQ.0b013e3181a4d506

Crigger, N. J., \& Meek, V. L. (2007). Toward a theory of self-reconciliation following mistakes in nursing practice. J Nurs Scholarsh, 39(2), 177-183. doi:10.1111/j.1547- 5069.2007.00164.x

Doucouliagos, H., Stanley, T.D. \& Viscusi, W. (2014). Publication selection and the income elasticity of the value of a statistical life. Journal of Health Economics, 33. 67-75. doi: 10.1016/j.jhealeco.2013.10.010

Elder, N. C., Brungs, S. M., Nagy, M., Kudel, I., \& Render, M. L. (2008). Nurses' Perceptions of Error Communication and Reporting in the Intensive Care Unit. Journal of Patient Safety, 4(3), 162-168. doi:10.1097/PTS.0b013e3181839b48

Espin, S., Lingard, L., Baker, G. R., \& Regehr, G. (2006). Persistence of unsafe practice in everyday work: an exploration of organizational and psychological factors constraining safety in the operating room. Qual Saf Health Care, 15(3), 165-170. doi:10.1136/qshc.2005.017475

Gallagher, T., Waterman, A., Ebers, A., Fraser, V., \& Levinson, W. (2003). Patients' and physicians' attitudes regarding the disclosure of medical errors. The Journal of the American Medical Association , 289, 1001-1007. doi:10.1001/jama.289.8.1001

Glaser, B. G., \& Strauss, A. L. (1967). The discovery of grounded theory; strategies for qualitative research. Chicago,: Aldine Pub. Co.

Goodman, J., Villarreal, P., \& Jones, B. (2011). The Social Cost of Adverse Medical Evens, and What We Can Do About It. Health Affairs, 30(4), 590-595. doi:10.1377/hlthaff.2010.1256

Griffin, F. A., \& Resar, R. K. (2009). HI Global Trigger Tool for Measuring Adverse Events (Second Edition). Retrieved from Cambridge, MA: http://www.ihi.org/resources/Pages/IHIWhitePapers/IHIGlobalTriggerToolWhitePaper .aspx/ 
Hall, L., \& Scott, S. (2012). The second victim of adverse health care events. Nursing Clinics of North America, 47, 383-393. doi:10.1016/j.cnur.2012.05.008

Harkanen, M., Kervinen, M., Ahonen, J., Voutilainen, A., Turunen, H., \& VehilainenJulunen, K. (2015). Patient-specific risk factors of adverse drug events in adult inpatients - evidence detected using the Global Trigger Tool method. Journal of Clinical Nursing, 24(3/4); 528-591. doi: 10.1111/jocn.12714

Hartnell, N., MacKinnon, N., Sketris, I., \& Fleming, M. (2012). Identifying, understanding and overcoming barriers to medication error reporting in hospitals: a focus group study. BMJ Qual Saf, 21. 361-368. doi:10.1136/bmjqs-2011-000299.

Hershey, K. (2015). Culture of Safety. Nurs Clin N Am, 50. 139-152. doi: 10.1016/j.cnur.2014.10.011

Hession-Laband, E., \& Mantell, P. (2011). Lessons learned: use of event reporting by nurses to improve patient safety and quality. J Pediatr Nurs, 26(2), 149-155. doi:10.1016/j.pedn.2010.12.005

James, J. (2013). A New, Evidenced-based Estimate of Patient Harms Associated with Hospital Care. Journal of Patient Safety, 9(3), 122-128.

Jeffe, D. B., Dunagan, W. C., Garbutt, J., Burroughs, T. E., Gallagher, T. H., Hill, P. R., . . Fraser, V. J. (2004). Using focus groups to understand physicians' and nurses' perspectives on error reporting in hospitals. Jt Comm J Qual Saf, 30(9), 471-479. Retrieved from http:/www.ncbi.nlm.nih.gov/pubmed/15469124

Jones, J., \& Treiber, L. (2012). When nurses become the 'second' victim. Nursing Forum, 47, 286-291. doi:10.1111/j.1744-6198.2012.00284.x

Kachalia, A., Mello, M., Nallamothu, B., Studdert, D.,(2016). Legan and policy interventions to improve patient safety.Circulation, 133(7) 661-671. doi: 10.1161/CIRCULATIONAHA.115.015880

Karga, M., Kiekkas, P., Aretha, D., \& Lemonidou, C. (2011). Changes in nursing practice: Associations with responses to and coping with errors. Journal of Clinical Nursing, 20, 3246-3255. doi:10.1111/j.1365-2702.2011.03772.x

Kiekkas, P. Karga, M., Lemonidou, C., Aretha, D., Karanikolas, M. (2011). Medication errors in critically ill adults: a review of direct observation evidence. American Journal of Critical Care, 20(1). 36-44. doi: 10.4037/ajcc2011331

Kohn, L. T., Corrigan, J., \& Donaldson, M. S. (2000). To err is human : building a safer health system. Washington, D.C.: National Academy Press.15 
Landrigan, C. P., Rothschild, J. M., Cronin, J. W., Kaushal, R., Burdick, E., Katz, J. T., . . .Czeisler, C. A. (2004). Effect of reducing interns' work hours on serious medical errors in intensive care units. $N$ Engl J Med, 351(18), 1838-1848. doi:10.1056/NEJMoa041406

Leape, L., Berwick, D., Clancy, C., Conway, J., Gluck, P., Guest, J., . . . Lucian Leape Institute at the National Patient Safety, F. (2009). Transforming healthcare: a safety imperative. Qual Saf Health Care, 18(6), 424-428. doi:10.1136/qshc.2009.036954

Lewis, E., Baernholdt, M., \& Hamrick A. (2013). Nurses' experience of medical errors: An integrative literature review. Journal of Nursing Care and Quality, 28, 153161. doi:10.1097/NCQ.0b013e31827e05d1

Lewis, E., Baernholdt, M., Yan, G. \& Guterbock, T. (2015). Relationship of adverse events and support to RN burnout. J nurse Cal Qual,30(2). 144-152. doi:10.1097/NCQ.0000000000000084

Loeb, J. M., \& O'Leary, D. S. (2004). The fallacy of the body count: Why the interest in patient safety and why now? In B. J. Youngberg \& M. J. Hatlie (Eds.), The patient safety handbook (pp. xx, 779 p.). Sudbury, MA: Jones and Bartlett.

Mull, H., Brennan, C., Chan, J., Rosen, A., Simon, S., ... Hermons, J. (2015). Identifying previously undetected harm: Piloting the Institute for Healthcare Improvement's Global Trigger Tool in the Veterans' Health Administration. Quality Management in Health Care, 24(3). 140-146. doi: 10.1097/QMH.0000000000000060

Osmon, S., Harris, C. B., Dunagan, W. C., Prentice, D., Fraser, V. J., \& Kollef, M. H. (2004). Reporting of medical errors: an intensive care unit experience. Crit Care Med, 32(3), 727-733. Retrieved from http://www.ncbi.nlm.nih.gov/pubmed/15090954

Page, A. (2004). Keeping patients safe: transforming the work environment of nurses. Washington, DC: National Academies Press.

Paparella, S. (2011). Caring for the caregiver: Moving beyond the finger pointing after an adverse event. Journal of Emergency Nursing, 37, 263-265. doi:10.1016/j.jen.2011.01.001

Pham, J., Frick, K., \& Pronovost, P. (2013). Why don't we know whether care is safe? American Journal of Medical Quality, 28(6). 457-463. doi: $10.1177 / 1062860613479397$

Plews-Ogan, M., Owens, J., \& May, N. (2013). Wisdom through adversity: learning and growing in the wake of an error. Patient Education and Counseling, 91. 236-242. doi: 10.1016/j.pec.2012.12.006 
Prang, I., Jelsness-Jorgensen, L. (2014). Should I report? A qualitative study of barriers to incident reporting among nurses working in nursing homes. Geriatric Nursing, 35. 441-447. doi:10.1016/j.gerinurse.2014.07.003

Pronovost, P. J., Miller, M. R., \& Wachter, R. M. (2006). Tracking progress in patient safety: an elusive target. JAMA, 296(6), 696-699. doi:10.1001/jama.296.6.696

Rowin, E. J., Lucier, D., Pauker, S. G., Kumar, S., Chen, J., \& Salem, D. N. (2008). Does error and adverse event reporting by physicians and nurses differ? Jt Comm J Qual Patient Saf, 34(9), 537-545.

Schwappach D., \& Boluarte, T. (2009). The emotional impact of medical error involvement on physicians: A call for leadership and organizational accountability. Swiss Medical Weekly, 139, 9-15. Retrieved from: http://www.mitsstools.org/uploads/3/7/7/6/3776466/smw-aop12417.pdf

Schelbred, A., \& Nord, R. (2007). Nurses' experiences of drug administration errors. Journal of Advanced Nursing, 60, 317-324. doi: 10.1111/j.13652648.2007.04437.x

Scott, S., Hirschinger, L., Cox, K., McCoig, M., Brandt, J., \& Hall, L. (2009). The natural history of recovery for the healthcare provider "second victim" after adverse patient events. Quality and Safety in Health Care, 18, 325-330. doi:10.1136/qshc.2009.032870

Seys, D., Scott, S., Wu, A., VanGerven, E., Vleugels, A., Euwema, M. .. Vanhaecht, K. (2013). Supporting involved health care professional (second victims) following an adverse health event: A literature review. International Journal of Nursing Studies, 50, 678-687. doi:10.1016/j.ijnurstu.2012.07.006

Sirriyeh, R., Lawton, R., Gardner, P., \& Armitage, G. (2010). Coping with medical error: a systematic review of papers to assess the effects of involvement in medical errors on healthcare professionals' psychological well-being. Qual Saf Health Care, 19(6), e43. doi:10.1136/qshc.2009.035253

Steege, L., Drake, D., Olivas, M. \& Mazza, G. (2015). Evaluation of physically and mentally fatiguing tasks and sources of fatigue as reported by registered nurses. Journal of Nursing Managememt, 23. 179-189. doi: 10.1111/jonm.12112

Stratton, K. M., Blegen, M. A., Pepper, G., \& Vaughn, T. (2004). Reporting of medication errors by pediatric nurses. J Pediatr Nurs, 19(6), 385-392. doi:10.1016/j.pedn.2004.11.007

Taylor, J. A., Brownstein, D., Christakis, D. A., Blackburn, S., Strandjord, T. P., Klein, E. J., \& Shafii, J. (2004). Use of incident reports by physicians and nurses to 
document medical errors in pediatric patients. Pediatrics, 114(3), 729-735. doi:10.1542/peds.2003-1124-L

Uribe, C. L., Schweikhart, S. B., Pathak, D. S., Dow, M., \& Marsh, G. B. (2002). Perceived barriers to medical-error reporting: an exploratory investigation. $J$ Healthc Manag, 47(4), 263-279. Retrieved from http://www.ncbi.nlm.nih.gov/pubmed/12221747

Viscusi, W. K. (2003). The value of life: estimates with risk by occupation and industry. Discussion Paper No. 422. Harvard Law School. Cambridge, MA. Retrieved from http://www.law.harvard.edu/programs/olin_center/papers/pdf/422.pdf

Waterman, A., Garbutt, J., Hazel, E., Dunagan, W., Levinson, W., Fraser, V., \& Gallagher, T. (2007). The emotional impact of medical errors on practicing physicians in the United States and Canada. The Joint Commission Journal on Quality and Patient Safety 33, 467-476. Retrieved from http://www.ingentaconnect.com/content/jcaho/jcjqs

Wieck, K.E. \& Sutcliffe, K. M. (2007). Managing the unexpected: Resilient performance in an age of uncertainty. (2nd edition). San Francisco, CA: Jossey-Bass

Wu, A. (2000). Medical error: The second victim. BMJ, 320, 726-727. doi:10.1136/bmj.320.7237.726

Wu, A. \& Steckelberg, R. (2012). Medical error, incident investigation and the second victim: doing better but feeling worse? BMJ Qual Saf, 21(4). 267-270. doi:10.1136/bmjqs-2011-000605

4. Sitterding, M. C., Ebright, P., Broome, M, \& Patterson, E.S. (2014). Situation awareness and interruption handling during medication administration. Western Journal of Nursing Research, DOI: 10.1177/0193945914533426.

5. *Ebright, P., (Jan. 31, 2010) "The Complex Work of RNs: Implications for Healthy Work Environments" OJIN: The Online Journal of Issues in Nursing Vol. 15, No. 1, Manuscript 4.DOI : 10.3912/OJIN.Vol15No01Man04 
HALL L.M., FERGUSON-PARÉ M., PETER E., WHITE D., BESNER J., CHISHOLM A., FERRIS E., FRYERS M., MACLEOD M., MILDON B., PEDERSEN C. \& HEMINGWAY A. (2010) Going blank: factors contributing to interruptions to nurses' work and related outcomes Journal of Nursing Management 18, 1040-1047

Hopkinson, S. G. and Jennings, B. M. (2013), Interruptions during nurses' work: A state-of-thescience review. Res. Nurs. Health, 36: 38-53. doi: 10.1002/nur.21515

Foroughi CK, Werner NE, Nelson ET, Boehm-Davis. D.A.. Do interruptions affect quality of work? Hum Factors 2014;56:1262-71. 